\title{
Research on the Distribution Characteristics of Chinese Wushu in Northern Europe
}

\author{
Xiaoxue Liu ${ }^{1}$, Yanfen Zhang ${ }^{2}$, and Xuezhi $\mathrm{Ma}^{3}$ \\ ${ }^{1}$ Department of Physical Education, China University of Geosciences, Xueyuan Road, Haidian \\ District, Beijing, P. R. China \\ ${ }^{2}$ Department of Life Sciences; Xinxiang University, Xinxiang Henan Province, Eastern Section of \\ Hua Lan Road, Hongqi District, Xinxiang City, Henan, China \\ ${ }^{3}$ Beijing Sport University Wushu School, Information Road, Haidian District, Beijing, China \\ xxliu8888@aliyun.com,1421185078@qq.com, malaoshide21@sohu.com
}

Keywords: Chinese Wushu, Northern Europe, Spreading, Distribution, Challenges

Abstract: This paper studies the distribution characteristics of Chinese Wushu single associations and Wushu fitness clubs in northern Europe, and analyzes the problems for Chinese Wushu's spreading to Northern Europe through literature review, field survey, mathematical statistics and other research methods.

\section{Research Objects and Methods}

\subsection{Research Objects}

The objects include the projects carrier, fitness clubs, single sports associations, and club coaches of Chinese Wushu during spreading to Northern Europe.

\subsection{Research Methods}

\subsubsection{Literature Review}

Relevant literature is collected from National Library of China, China Journal Net, the Nordic government websites, official websites for Wushu associations of Nordic countries (www.martialarts.dk; www.kampsport.no; www.heilsudrekinn.is), and Club Websites of Nordic countries.

\subsubsection{Field Survey}

Field survey is not only a basic research method for ethnology and anthropology, but also the most primary and basic method to get first-hand research data. The author has widely interviewed the heads of relevant associations in Nordic countries and a large number of club members when coaching and publicizing Wushu, conducting regimen, lion dance and other projects in Norwegian Confucius Institute. 


\subsubsection{Expert Consulting and Questionnaire Survey}

The author conducted questionnaire surveys and interviews among experts and coaches who spread Chinese Wushu at the front-line and heads of the Cultural Offices of Embassy in five Nordic countries, persons in charge of relevant associations in Nordic countries and local scholars.

\section{Results Analysis}

\subsection{Characteristics of Chinese Wushu’s Spreading to Northern Europe}

According to Chinese Traditional Sports, currently, 676 kinds of minority traditional sports and 301 kinds of Han traditional sports have been explored and found in China. With the cultural exchange between China and the Nordic countries gradually accelerating, Chinese Wushu projects' spreading to Nordic countries has assumed a diversified trend. Under the leadership of Chinese Wushu (Chinese Kung Fu), Chinese national traditional sports, together with conducting regimen (Qigong), dragon and lion dances, kites, dragon boat, shuttlecock, Chinese-style wrestling and other projects, have also entered the Nordic countries.

As the questionnaire investigation shows, according to the distribution statistics of the health clubs projects, Denmark boasts 118 health clubs of Chinese traditional projects (share of $13.14 \%$, the main projects are Tai Chi and Wing Chun), which are more than that of any Nordic countries. Finland has 115 clubs (share of 8.29\%,Taijiquan, Shaolin boxing and Wing Chun respectively occupying one third), Sweden 85 (7.45\%, Wing Chun, Shaolin Boxing and Qigong respectively occupying one third, and Tai Chi mostly being carried out in an integrated project club), Norway 16 (3.84\%), Iceland 3 (3.84\%). Norway has 16, including 14 clubs registered officially and 2 clubs being registered; The 85 clubs recognized by Swedish Single Association incorporate Jeet Kune Do into Chinese Wushu projects, mainly because the club which names after "Jeet Kune Do" carries out teaching and training of Jeet Kune Do while operating teaching and training of other Chinese martial arts, such as Wing Chun.

\subsection{Development Characteristics of National Single Associations during Chinese Wushu's Spreading to Northerm Europe}

Currently, the national single associations in the Nordic countries are relatively few in number, focusing on the martial arts, lion dance, Qigong, dragon boat, kite, shuttlecock, among which martial arts, Qigong, lion dance dominate in the Nordic countries. While other items such as kites, dragon boat, shuttlecock, wrestling, dragon dance and so on do not form large scale in Northern Europe (Zhou Weiliang, 2003.) because they are easily affected by the weather or the equipment. For example, affected by local climate, kites and dragon boat only have a short seasonal training in Northern Europe during the promotion process (in Northern Europe, there are more than 15 hours of darkness per day in half a year). While the dragon boat project training mainly depends on the sailing club (Qiu Pixiang, 2008.). The dragon dance needs relatively high-level equipment. Due to the requirement for large number of people to participate in the exercise and unfixed persons, dragon boat suffers great limitation in carrying out and popularizing in Northern Europe (Lu Bing, 2005.). Wrestling and shuttlecock started late in Northern Europe and have not yet formed regional advantages. However, Wushu, lion dance and Qigong are often carried out in the same club and have become popular in Nordic countries with parallel development and mutual promotion. 


\subsection{Development Characteristics of Chinese Wushu in Nordic Single Associations and Clubs}

\subsubsection{Development Characteristics of Chinese Wushu in Nordic Clubs}

The Nordic countries have started to introduce "kite”, “dragon boat” (Feng Tianyu, 1990.) as local official sports, and organized kite and dragon boat races. For example, Finland, Denmark and Sweden have also set up Dragon Boat Associations of NGOs (University of Copenhagen Dragon Boat Association, Uppsala City Dragon Boat Association and so on). Among them, Finland has established national single association of dragon boat, and has hosted and participated in international dragon boat races. Denmark and Finland have also set up the "kite" single association, and participated in competitions and communication activities (Liang Shuming, 2005.) in Weifang, Shandong province of China many times.

\subsubsection{Analysis on Characteristics of Coaches in Health Clubs during Chinese Wushu's spreading in the Northerm Europe}

Chinese Wushu has spread in the Northern Europe for nearly a century, and the earliest group of spreaders are mainly Chinese immigrants, including Chinese laborers who came from Germany and France and were forced to migrate to the Nordic countries during World War I, Chinese descendants who came from Vietnam, Myanmar, China, India and other countries and took refuge in Northern Europe. In addition, when the government of old China established official exchanges with Nordic countries about 1915 years ago (until 1949), some Chinese studied abroad or immigrated to Nordic countries, and some students were detained and settled down there after finishing their studies due to wars and other reasons.

According to different historical stages of Chinese Wushu's spreading to the Northern Europe, the coaches of the Nordic Wushu (martial arts) clubs can be divided into five groups. The first group includes those who immigrated to the Northern Europe and engaged in spreading Chinese Wushu, and their descendants have inherited the tradition. The second group includes those who immigrated to or worked in Northern Europe after the founding of New China, especially after China's reform and opening up. They can also be classified as professionals and relevant practitioners engaged in coaching Chinese national traditional Sports. The third group includes personnel on government sponsorship who publicized and popularized Chinese Wushu in Northern Europe in a short term in the 1980s, some high-level professional and technical personnel of whom started a long-term coaching career. The fourth group includes societies or associations set up by Chinese overseas students to promote Chinese national traditional Sports. The fifth group includes student or disciples of Chinese immigrants, those native Nordic who learned Chinese Wushu earlier without having visited China, and those native Nordic who returned to Nordic countries to coach after having learned Chinese Wushu in China since the establishment of the PRC China.

\section{Opportunities And Challenges for Chinese Wuhu's Developing In Northern Europe}

The Northern Europe has a population of about 25 million people. The per capita income of Nordic people is about \$ 35,000 per year, and the Northern Europe is one of the regions where the highest income and consumption levels exist around the world. The total number of Nordic fitness clubs based on Chinese national traditional sports is about 337, accounting for about $8 \%$ of the total number of Nordic "Wushu" clubs (approximately 3863 clubs), while per 74,000 people share one Chinese national traditional sports club. Therefore, concerning the absolute number of clubs, Chinese Wushu has broad prospects for development in the Nordic market (as listed below): 
Table 1 List of Chinese Traditional Sports and Fitness Clubs in Nordic Countries

\begin{tabular}{|l|l|l|l|l|l|l|}
\hline Country & Clubs & Chinese(\%) & Karate (\%) & Taekwondo(\%) & $\begin{array}{l}\text { Brazilian } \\
\text { Jiu-jitsu(\%) }\end{array}$ & $\begin{array}{l}\text { Muay } \\
\text { Thai (\%) }\end{array}$ \\
\hline Denmark & 898 & $118(13.14)$ & $203(22.61)$ & $90(10.02)$ & $19(2.12)$ & $34(3.79)$ \\
\hline Norway & 417 & $16(3.84)$ & $139(33.33)$ & $95(10.58)$ & $17(4.08)$ & $8(1.92)$ \\
\hline Finland & 1388 & $115(8.29)$ & $191(13.76)$ & $110(7.93)$ & $22(1.59)$ & $25(1.80)$ \\
\hline Iceland & 19 & $3(15.79)$ & $7(36.84)$ & $6(31.58)$ & - & - \\
\hline Sweden & 1141 & $85(7.45)$ & $324(28.40)$ & $83(7.27)$ & $37(3.24)$ & $42(3.68)$ \\
\hline Total & 3863 & $337(8.72)$ & $864(22.37)$ & $384(9.94)$ & $95(2.46)$ & $109(2.82)$ \\
\hline
\end{tabular}

As the table 1 shows(Data source: according to data of Wushu Associations of Nordic Countries, www.martialarts.dk; www.kampsport.no; www.kamppailulajit.net; www.heilsudrekinn.is; www.budokampsport.se), the total number of fitness clubs based on Chinese Wushu, Qigong and lion dance in the Nordic market has reached 337, of which Denmark covers 118, Norway 16, Finland 115, Iceland 3, Sweden 85. Compared with traditional sports development of the third-country in Northern Europe, Brazilian jiu-jitsu only has 95 clubs in the Nordic, while Muay Thai only 109, which is far less than the number of Chinese national traditional sports clubs. Besides, the number of Chinese national traditional sports clubs is no less than that of Korean taekwondo clubs, even though Korean taekwondo is an Olympic project.

\section{Conclusions and Suggestions}

\subsection{Conclusion}

As described herein, the spread and development of Chinese Wushu projects in the Nordic countries have formed a considerable scale from the establishment of single associations of projects to the absolute share of the clubs number. Both are at an unprecedented level, and there are seven kinds of associations (including Wushu single associations, as well as dragon and lion dance, Qigong, shuttlecock, kites and dragon boat associations, etc.). Both of Finland and Denmark have established six associations (there are four national associations in Finland, with the highest level and the largest number). Sweden has established seven projects associations, which is the largest number. Norway and Iceland have less project associations and lower level (only three projects associations).

The number of clubs in the Nordic region has reached as many as 337, of which there are 118 clubs in Denmark (13.14\% share, dominated by Tai Chi and Wing Chun training). Finland has 115 clubs (market share $8.29 \%$, of which Tai Chi, Wing Chun and Shaolin boxing respectively cover about one-third), Sweden 85 (7.45\%, of which Wing Chun, Shaolin boxing and qigong respectively cover one-third each, and Tai Chi training mostly is conducted in integrated projects clubs), Norway 16 (3.84\%), Iceland 3 (3.84\%). The number of Chinese national traditional sports clubs is no less than that of Korean taekwondo clubs, even though Korean taekwondo is an Olympic project. The number is far more than that of clubs in other countries (109 Muay Thai Clubs, 95Brazilian Jiu Jitsu Clubs). However, compared with Japan national clubs (864 karate clubs), it still has a long way to go. 


\subsection{Suggestions}

With the number of Chinese national and traditional associations established in the Nordic region increasing, many problems appear, such as the appearing of low level of projects associations in general. While most of them are at regional or municipal level, as a result, the influence and development of projects are greatly influenced. It is suggested that China should sign relevant agreements based on mutual benefits with the Nordic countries from the aspect of introducing projects, discussing on the level of the relevant single associations, and providing corresponding technical support and human resources assistance.

In Northern Europe, the absolute number of health clubs based on Wushu is large, but they have been established there for a short period, and there is a direct relationship between the number of clubs and the economic development, policy support and technical inputs. Under the premise that Chinese economic aggregate greatly increases in the first stage, it is suggested that the Chinese government should strengthen economic and technical inputs for Chinese Wushu to spread in the region, and strive to improve the construction which regards health clubs as economic entity so as to lay a solid material and technological foundation for the development of the project through cultural spread and technical inputs.

\section{Acknowledgements}

This paper is supported by "Project of the humanities and social sciences research program of the Ministry of education of China" (15YJA890016), Basic scientific research projects in Chinese Universities (2-9-2015-417) and China University of Geosciences (Beijing) key project of teaching reform (JGZHD201711).

\section{References}

[1] Bing Lu, 2005. Introduction to Chinese Traditional Sports Culture, National Publishing House. Beijing, 1 st edition.

[2] Pixiang Qiu, 2008. Introduction of National Traditional Sports, Higher Education Press. Beijing, 1st edition.

[3] Shuming Liang, 2005. Chinese Culture, Shanghai People’s Publishing House. Shanghai, 1st edition.

[4] Tianyu Feng, 1990. The Cultural History of China, Shanghai People's Publishing House. Shanghai, 1st edition.

[5] Weiliang Zhou, 2003. Advanced Course for Introducing Chinese Traditional Sports, Higher Education Press. Beijing, 1st edition. 